\title{
Balloon Aortic Valvuloplasty in Degenerative Aortic Stenosis: Therapeutic Impact on Patients In Extremis
}

\author{
Vitor de Andrade Vahle1, Fábio Augusto Pinton², Eduardo França Pessoa de Melo \\ Cristiano Guedes Bezerra ${ }^{4}$, Marco Antônio Perin ${ }^{5}$, Santiago Raul Arrieta ${ }^{6}$, Luiz Junya Kajita \\ José Mariani Junior ${ }^{8}$, Antônio Esteves Filho ${ }^{9}$, Expedito Eustáquio Ribeiro da Silva ${ }^{10}$, \\ Flávio Tarasoutchi ${ }^{11}$, Max Grinberg ${ }^{12}$, Pedro Alves Lemos Neto ${ }^{13}$
}

\begin{abstract}
Background: Balloon aortic valvuloplasty (BAV) is used as a palliative strategy in patients who are not eligible for valve replacement surgery, transcatheter aortic valve implantation, or as a bridge to these treatment modalities. The impact of $\mathrm{BAV}$ as a salvage procedure for patients in extreme clinical conditions (in extremis) is unknown. Methods: Patients with severe degenerative aortic stenosis undergoing BAV between July 2008 and January 2013 were evaluated. Patients were divided into the in-extremis group (defined by the presence of two or more of the following organ dysfunctions: mechanical ventilation, hemodynamic instability, dialysis, coagulopathy or severe hepatic dysfunction) and the control group, which included the remaining patients. Results: A total of 19 patients underwent BAV. The clinical condition in-extremis was present in $42.1 \%$ of them. Patients from the in-extremis group had a higher EUROSCORE II $(41.1 \pm 24.7$ vs. $15.9 \pm 14.0 ; \mathrm{P}=0.001)$ and LV ejection fraction lower than the control group (33.9 $\pm 17.3 \%$ vs. $49.0 \pm 12.5 ; \mathrm{P}=0.04)$. None of the patients in the in-extremis group survived past the hospitalization period,
\end{abstract}

\section{RESUMO}

Valvuloplastia Aórtica por Cateter Balão na Estenose Aórtica Degenerativa: Impacto Terapêutico em Pacientes em Condição Clínica In Extremis

Introdução: A valvuloplastia aórtica por cateter balão (VAB) é utilizada como estratégia paliativa em pacientes inelegíveis tanto para troca valvar cirúrgica quanto para implante valvar aórtico transcateter, ou como ponte para essas modalidades de tratamento. Não se sabe o impacto terapêutico da VAB quando realizada como medida de salvamento para pacientes em condições clínicas extremas (in extremis). Métodos: Foram analisados pacientes com estenose aórtica grave de etiologia degenerativa submetidos à $\mathrm{VAB}$ entre julho de 2008 e janeiro de 2013. Os pacientes foram divididos entre o grupo in extremis (definido pela presença de duas ou mais das seguintes disfunções orgânicas: ventilação mecânica, instabilidade hemodinâmica, terapia renal dialítica, coagulopatia ou disfunção hepática graves) e o grupo controle, que incluiu os demais pacientes. Resultados: Um total de 19 pacientes realizaram
${ }^{1}$ Resident Physician at the Hemodynamics and Interventional Cardiology Service of Instituto do Coração do Hospital das Clínicas da Faculdade de Medicina da Universidade de São Paulo. São Paulo, SP, Brazil. ${ }^{2}$ Resident Physician at the Hemodynamics and Interventional Cardiology Service of Instituto do Coração do Hospital das Clínicas da Faculdade de Medicina da Universidade de São Paulo. São Paulo, SP, Brazil.

${ }^{3}$ Resident Physician at the Hemodynamics and Interventional Cardiology Service of Instituto do Coração do Hospital das Clínicas da Faculdade de Medicina da Universidade de São Paulo. São Paulo, SP, Brazil. ${ }^{4}$ Resident Physician at the Hemodynamics and Interventional Cardiology Service of Instituto do Coração do Hospital das Clínicas da Faculdade de Medicina da Universidade de São Paulo. São Paulo, SP, Brazil.

${ }^{5}$ Full professor. Interventionist Cardiologist Physician at the Hemodynamics and Interventional Cardiology Service of Instituto do Coração do Hospital das Clínicas da Faculdade de Medicina da Universidade de São Paulo. São Paulo, SP, Brazil.

${ }^{6}$ Interventionist Cardiologist Physician at the Hemodynamics and Interventional Cardiology Service of Instituto do Coração do Hospital das Clínicas da Faculdade de Medicina da Universidade de São Paulo. São Paulo, SP, Brazil.

7 Interventionist Cardiologist Physician at the Hemodynamics and Interventional Cardiology Service of Instituto do Coração do Hospital das Clínicas da Faculdade de Medicina da Universidade de São Paulo. São Paulo, SP, Brazil.

${ }^{8}$ Interventionist Cardiologist Physician at the Hemodynamics and Interventional Cardiology Service of Instituto do Coração do Hospital das Clínicas da Faculdade de Medicina da Universidade de São Paulo. São Paulo, SP, Brazil.

${ }^{9}$ Interventionist Cardiologist Physician at the Hemodynamics and Interventional Cardiology Service of Instituto do Coração do Hospital das Clínicas da Faculdade de Medicina da Universidade de São Paulo. São Paulo, SP, Brazil.

${ }^{10}$ Full professor. Interventionist Cardiologist Physician at the Hemodynamics and Interventional Cardiology Service of Instituto do Coração do Hospital das Clínicas da Faculdade de Medicina da Universidade de São Paulo. São Paulo, SP, Brazil.

11 Full professor. Cardiologist Physician at the Valve Disease Unit of Instituto do Coração do Hospital das Clínicas da Faculdade de Medicina da Universidade de São Paulo. São Paulo, SP, Brazil.

12 Full professor. Director of the Valve Disease Unit of Instituto do Coração do Hospital das Clínicas da Faculdade de Medicina da Uni-versidade de São Paulo. São Paulo, SP, Brazil.

13 Full professor. Director of the Hemodynamics and Interventional Cardiology Service of Instituto do Coração do Hospital das Clínicas da Faculdade de Medicina da Universidade de São Paulo. São Paulo, SP, Brazil.

Correspondence to: Pedro Alves Lemos Neto. Av. Dr. Enéas Carvalho de Aguiar, 44 - Jardim Paulista - São Paulo, SP, Brazil - CEP 05403-000 E-mail: pedro.lemos@incor.usp.br

Received on: 6/1/2013 • Accepted on: 8/18/2013 
whereas the control group mortality was $27.3 \%(P<0.01)$. Conclusions: BAV has an unfavorable result in patients with severe degenerative aortic stenosis with two or more organ dysfunctions, that is, patients in extremis.

DESCRIPTORS: Aortic valve stenosis. Balloon valvuloplasty. Heart valve prosthesis implantation.

D egenerative aortic stenosis is the valvulopathy whose incidence most increases with aging. Its prevalence in individuals over 75 years of age is estimated at $4.6 \% .^{1}$ The prognosis after the onset of symptoms is poor, with survival time between one and three years. ${ }^{2}$

The treatment of choice for symptomatic patients with severe aortic stenosis secondary to valve degeneration is aortic valve replacement surgery (AoVR). ${ }^{3}$ However, approximately $30 \%$ of these patients do not receive surgical treatment due to the high perioperative risk arising from multiple comorbidities. ${ }^{4}$ Thus, less invasive modalities have emerged for the treatment of this valvulopathy, among which stand out the transcatheter aortic valve implantation (TAVI) and balloon aortic valvuloplasty (BAV).

TAVI was safe and effective in patients with high surgical risk, providing a reduction in mortality in patients whose surgical procedure was refused by the surgeon because of an excess of clinical comorbidities. ${ }^{5}$ However, the anatomical prerequisites required, the high cost related to the procedure, and the low number of trained professionals capable of its performance make this option unavailable for most patients.

BAV is a procedure used as a palliative strategy in patients unfit for both surgical valve replacement and TAVI, or as a bridge to these treatment modalities. ${ }^{2,6-8}$ Its low cost and wide availability in most cardiology centers justify its use for patients with prohibitive surgical risk, despite the high recurrence rate of symptoms and its ineffectiveness in reducing mortality. 910

The best time to perform the BAV, in the context of symptomatic aortic stenosis, has not yet been defined. In most cases, the procedure is performed with urgency in patients refractory to optimized clinical treatment. In other times, however, BAV is performed as a measure to rescue patients who already present multiple organ dysfunctions, i.e., extreme clinical conditions (in
VAB no período. A condição clínica in extremis esteve presente em $42,1 \%$. Os pacientes do grupo in extremis tiveram EUROSCORE II mais elevado $(41,1 \pm 24,7$ vs. 15,9 \pm 14,0; $\mathrm{P}=0,01)$ e fração de ejeção do VE mais baixa que o grupo controle $(33,9 \pm 17,3 \%$ vs. $49,0 \pm 12,5 \% ; P=0,04)$. Nenhum paciente do grupo in extremis sobreviveu ao período intrahospitalar, enquanto que, no grupo controle, a mortalidade foi de $27,3 \%(P<0,01)$. Conclusões: Para o tratamento de pacientes com estenose aórtica grave de etiologia degenerativa, a VAB tem resultado desfavorável quando indicada para pacientes com duas ou mais disfunções orgânicas, ou seja, em condição clínica in extremis.

DESCRITORES: Estenose da valva aórtica. Valvuloplastia com balão. Implante de prótese de valva cardíaca.

extremis), in an attempt to avoid death, at the expense of an improvement in the cardiac output compromised by the aortic valve stenosis.

The aim of this study was to evaluate the therapeutic impact of BAV in the treatment of degenerative aortic stenosis in patients with and without the clinical condition in extremis.

\section{METHODS}

This is a retrospective study, conducted in a single quaternary care service of high complexity cardiology. The research was based on a database analysis and review of the electronic clinical record.

\section{Study population}

Between July 2008 and January 2013, all patients undergoing BAV for treatment of degenerative aortic stenosis at Instituto do Coração, Hospital das Clínicas da Faculdade de Medicina, Unniversidade de São Paulo (Incor-HCFMUSP), in São Paulo (SP) were reviewed. This study did not include procedures for treatment of congenital aortic stenosis.

\section{Procedure}

All procedures were performed by retrograde route, by puncturing the common femoral artery (right or left), and by the application of a long sheath with diameter 10F. Unfractionated heparin was administered to all patients. The size of the balloon catheter used in each procedure was chosen at the discretion of the surgeon. In some cases, the balloon inflation was preceded by a rapid stimulation (fast pacing), with a temporary pacemaker placed in the right ventricle.

The measurement of the aortic transvalvular gradient was performed before and after the BAV, through intracavitary manometry and transthoracic echocardiography. The sheath was removed immediately after the 
procedure, with subsequent manual compression for hemostasis.

Procedural success was defined as the successful dilation of the aortic valve with the balloon catheter, in the absence of complications during the procedure.

\section{Data collection}

Clinical, echocardiographic, and hemodynamic data, and in-hospital outcomes were obtained retrospectively from the electronic case notes of each patient treated at Incor-HCFMUSP. After hospital discharge, the evaluation of cardiovascular events was performed by analyzing the electronic records, with supplementation by telephone contact, when needed.

The patients' profile of disease severity was estimated by EuroSCORE II and STS Risk Score. Severe pulmonary hypertension was defined as a systolic pressure in pulmonary artery (SPPA) $\geq 60 \mathrm{mmHg}$ by echocardiography. Renal failure was characterized as the presence of creatinine clearance $\leq 60 \mathrm{~mL} / \mathrm{min}$.

The patients were divided in two groups: in extremis (defined by the presence of two or more of the following dysfunctions: mechanical ventilation, hemodynamic instability, renal dialysis therapy, coagulopathy, or severe liver dysfunction) and control, which included the remaining patients.

\section{Statistical analysis}

The analysis of clinical, echocardiographic, and hemodynamic data was performed using the software SPSS (IBM Corp., New York, USA). Continuous variables were described as mean and standard deviation and compared by Student's $t$-test. Categorical variables were described as frequency, and percentage, and compared by the chi-squared or Fisher's exact test, when appropriate. The survival analysis was performed by Kaplan-Meier method. A significance level of $\mathrm{P}<0.05$ was adopted.

\section{RESULTS}

A total of 19 patients with severe aortic stenosis with degenerative etiology were treated with BAV in the analyzed period. The study population was composed almost entirely by elderly people, and the mean age was $77.7 \pm 11.1$ years. The predominant symptom before the procedure was dyspnoea, and all patients were classified as heart failure functional class III or IV. Among the comorbidities, severe pulmonary hypertension was particularly prominent, with $31.6 \%$ of patients, and renal failure was present in $73.7 \%$. The mean of STS Risk Score was $36.6 \pm 17.4$ and that of EuroSCORE II was $26.5 \pm 22.6$. Other clinical characteristics of the patients are shown in Table 1.

Procedural success was achieved in $100 \%$ of the cases. The temporary pacemaker was used to promote rapid stimulation (fast pacing) in $68.4 \%$ of patients (Table 2). Significant reduction of the aortic transvalvular gradient was noted, both by echocardiography and by pressure measurements during the procedure (Figure 1).

The clinical condition in extremis was present in $42.1 \%$ of patients (Table 3 ). When compared to the control group, patients in the in extremis group were younger $(70.1 \pm 10.0$ vs. $83.3 \pm 8.5$ years; $P<0.01)$

TABLE 1

\section{Clinical characteristics}

\begin{tabular}{|c|c|}
\hline Variable & $n=19$ \\
\hline Age, years & $77.7 \pm 11.1$ \\
\hline Female, n (\%) & $13(68.4)$ \\
\hline Arterial hypertension, $\mathrm{n}(\%)$ & $9(47.4)$ \\
\hline Diabetes, n (\%) & $5(26.3)$ \\
\hline Dyslipidemia, n (\%) & $7(36.8)$ \\
\hline $\begin{array}{l}\text { Chronic obstructive pulmonary } \\
\text { disease, } \mathrm{n}(\%)\end{array}$ & $4(21.1)$ \\
\hline Severe pulmonary hypertension, n (\%) & $6(31.6)$ \\
\hline Renal failure, n (\%) & $14(73.7)$ \\
\hline Previous acute myocardial infarct, n (\%) & $4(21.1)$ \\
\hline Previous CABG surgery, n (\%) & $4(21.1)$ \\
\hline Previous coronary angioplasty, n (\%) & $3(15.8)$ \\
\hline Previous stroke, n (\%) & $1(5.3)$ \\
\hline \multicolumn{2}{|l|}{ Clinical picture, n (\%) } \\
\hline Heart failure functional class III or IV & $19(100)$ \\
\hline Angina & $5(26.3)$ \\
\hline \multicolumn{2}{|l|}{ Current medication, $\mathrm{n}(\%)$} \\
\hline Diuretic & $17(89.5)$ \\
\hline Digitalis & $5(26.3)$ \\
\hline Vasoactive drugs & $8(42.1)$ \\
\hline \multicolumn{2}{|l|}{ Risk scores } \\
\hline STS Risk Score & $36.6 \pm 17.4$ \\
\hline EuroSCORE II & $26.5 \pm 22.6$ \\
\hline Follow-up after discharge, days & $268.3 \pm 202.3$ \\
\hline
\end{tabular}

TABLE 2 Procedure characteristics

\begin{tabular}{lc}
\hline Variable & $\mathbf{n = 1 9}$ \\
\hline Success, n (\%) & $19(100)$ \\
Use of pacemaker for rapid stimulation, $\mathrm{n}(\%)$ & $13(68,4)$ \\
Vascular complications, $\mathrm{n}(\%)$ & 0 \\
Stroke, n $(\%)$ & 0 \\
Death during the procedure, $\mathrm{n}(\%)$ & 0 \\
\hline
\end{tabular}


and had higher EuroSCORE II (41.1. \pm 24.7 vs. 15.9 \pm 14.0l; $P<0.01)$. In addition, the in extremis group had a lower left ventricle ejection fraction before the procedure versus the control group $(33.9 \pm 17.3 \%$ vs.

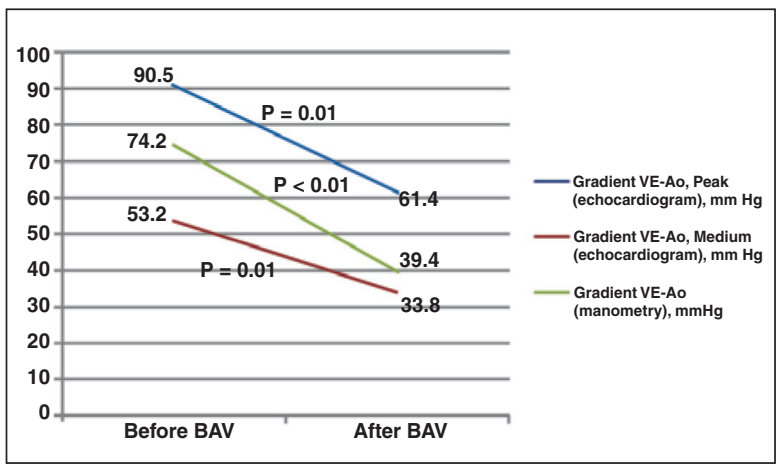

Figure 1 - LV-Ao gradient before and after balloon aortic valvuloplasty. $\mathrm{LV}$, left ventricle, Ao, aorta; BAV, balloon aortic valvuloplasty.

TABLE 3

Clinical characteristics by group

\begin{tabular}{|c|c|c|c|}
\hline Variable & $\begin{array}{l}\text { In extremis } \\
\quad(n=8)\end{array}$ & $\begin{array}{l}\text { Control } \\
(n=11)\end{array}$ & $\mathbf{P}$ \\
\hline Age, years & $70.1 \pm 10.0$ & $\begin{array}{c}83.3 \pm \\
8.5\end{array}$ & $<0.01$ \\
\hline Female, n (\%) & $6(75.0)$ & $7(63.6)$ & 0.60 \\
\hline $\begin{array}{l}\text { Systemic arterial } \\
\text { hypertension, n (\%) }\end{array}$ & $3(37.5)$ & $6(54.5)$ & 0.46 \\
\hline Diabetes, n (\%) & $3(37.5)$ & $2(18.2)$ & 0.35 \\
\hline Dyslipidemia, n (\%) & $2(25.0)$ & $5(45.5)$ & 0.36 \\
\hline $\begin{array}{l}\text { Chronic obstructive } \\
\text { pulmonary disease, n (\%) }\end{array}$ & $3(37.5)$ & $1(9.1)$ & 0.13 \\
\hline $\begin{array}{l}\text { Severe pulmonary } \\
\text { hypertension, n (\%) }\end{array}$ & $3(37.5)$ & $3(27.3)$ & 0.64 \\
\hline Renal failure, n (\%) & $7(87.5)$ & $7(63.6)$ & 0.24 \\
\hline $\begin{array}{l}\text { Acute myocardial } \\
\text { infarction, } \mathrm{n}(\%)\end{array}$ & $1(12.5)$ & $3(27.3)$ & 0.44 \\
\hline Previous CABG, n (\%) & $1(12.5)$ & $3(27.3)$ & 0.44 \\
\hline $\begin{array}{l}\text { Previous coronary } \\
\text { angioplasty, n (\%) }\end{array}$ & $0(0)$ & $3(27.3)$ & 0.11 \\
\hline Previous stroke, n (\%) & $0(0)$ & $1(9.1)$ & 0.38 \\
\hline Vasoactive drugs use & $6(75.0)$ & $2(18.2)$ & 0.01 \\
\hline \multicolumn{4}{|l|}{ Risk scores } \\
\hline STS Risk Score & $45.1 \pm 15.9$ & $\begin{array}{l}30.4 \pm \\
16.3\end{array}$ & 0.07 \\
\hline EuroSCORE II & $41.1 \pm 24.7$ & $\begin{array}{c}15.9 \pm \\
14.0\end{array}$ & 0.01 \\
\hline
\end{tabular}

$49.0 \pm 12.5 \% ; P=0.04)$. Hemodynamic and echocardiographic characteristics are shown in Table 4.

In both groups, there were no deaths during the procedure. None of the eight patients in the in extremis group survived the in-hospital period, while in the control group the in-hospital mortality was $27.3 \%$ $(\mathrm{P}<0.01)$. Survival at 180 days is shown in Figure 2.

Three patients $(15.8 \%)$ of the control group were submitted to BAV as a bridge to other definitive treatment: one patient underwent TAVI by transapical approach and died during the procedure, and two patients underwent AoVR (one of them was discharged and the other died in the immediate postoperative period). All patients who were discharged $(42.1 \%$ ) showed improvement in their heart failure functional class. The mean follow-up was $268.3 \pm 202.3$ days.

\section{DISCUSSION}

This study was relevant in the analysis of the clinical, echocardiographic, and hemodynamic characteristics, as well as in the evolution of patients with severe degenerative aortic stenosis treated by BAV.

The high in-hospital mortality in the study reflects the clinical profile of extreme severity of the patients, mainly due to the presence of multiple comorbidities. There are no other studies in the literature that include a group of patients as severe as those described in this work. The mean STS Risk Score in the PARTNER study, ${ }^{5}$ which included only patients at high surgical risk or considered inoperable, was $11.6 \pm 6.0$, i.e., much lower than that of the present study $(36.6 \pm 17$, 4). Other studies involving only patients undergoing BAV also included patients with less severe conditions compared to the present study, with lower incidence of comorbidities and with lower risk scores. ${ }^{6,7,11-14}$

Most patients $(73.7 \%)$ showed renal failure at the time of the procedure, and most had pulmonary artery pressure $>60 \mathrm{mmHg}$. Both conditions have been associated to an increase in mortality in earlier studys. ${ }^{9,15}$

In a study of 509 patients, Ben-Dor et al. demonstrated that the mortality after 5 months for patients with SPPA $>60 \mathrm{mmHg}$ was $49.1 \%$, regardless of the type of treatment received (BAV, TAVI, or AoVR). ${ }^{16}$

Several studies have correlated the presence of renal insufficiency before the procedure with increased mortality. ${ }^{9,17,18}$ A study of 262 patients at high surgical risk undergoing BAV showed that creatinine clearance $\leq 60 \mathrm{~mL} / \mathrm{min}$ before the procedure is a strong predictor of mortality. ${ }^{7}$

The absence of vascular complications in this study may be related to the use of sheaths with small calibre (10F) in all patients, as well as to the immediate withdrawal of the sheath. Despite being related to a shorter hospital stay and a lower rate of blood transfusions in 
TABLE 4

Hemodynamic and echocardiographic characteristics

\begin{tabular}{|c|c|c|c|}
\hline Variable & $\begin{array}{c}\text { In extremis } \\
(\mathrm{n}=8)\end{array}$ & $\begin{array}{l}\text { Control } \\
(n=11)\end{array}$ & $\mathbf{P}$ \\
\hline \multicolumn{4}{|l|}{ Before valvuloplasty } \\
\hline LV-Ao gradient (manometry), $\mathrm{mmHg}$ & $70.6 \pm 25.1$ & $76.8 \pm 23.1$ & 0.59 \\
\hline LV-Ao gradient, peak (echocardiogram) mmHg & $96.9 \pm 35.6$ & $85.9 \pm 23.4$ & 0.43 \\
\hline LV-Ao gradient, medium (echocardiogram) mmHg & $55.9 \pm 22.1$ & $51.3 \pm 15.8$ & 0.60 \\
\hline Ejection fraction, $\%$ & $33.9 \pm 17.3$ & $49.0 \pm 12.5$ & 0.04 \\
\hline Moderate or severe aortic regurgitation, n (\%) & $1(12.5)$ & $2(18.2)$ & 0.54 \\
\hline \multicolumn{4}{|l|}{ After valvuloplasty } \\
\hline LV-Ao gradient (manometry), $\mathrm{mmHg}$ & $41.3 \pm 21.5$ & $38.0 \pm 24.9$ & 0.77 \\
\hline LV-Ao gradient, peak (echocardiogram) mmHg & $66.8 \pm 19.2$ & $57.5 \pm 20.5$ & 0.34 \\
\hline LV-Ao gradient, medium (echocardiogram) mmHg & $31.8 \pm 18.9$ & $35.3 \pm 12.3$ & 0.63 \\
\hline Ejection fraction, $\%$ & $39.1 \pm 15.9$ & $52.7 \pm 13.8$ & 0.06 \\
\hline Moderate or severe aortic regurgitation, n (\%) & $2(25.0)$ & $3(27.3)$ & 0.36 \\
\hline
\end{tabular}

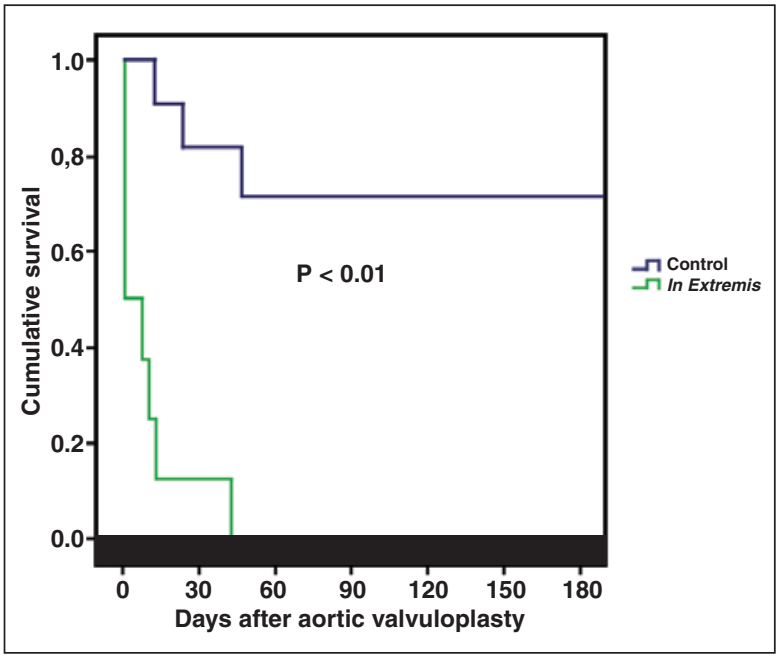

Figure 2 - Survival after aortic balloon valvuloplasty.

patients undergoing AoBV, ${ }^{19}$ vascular occlusion devices were not used in this study.

The division of patients according to the presence or absence of the clinical condition in extremis was extremely important for the understanding of the most appropriate time for performing BAV. The guidelines do not address BAV as a salvage therapy in patients in critical clinical condition with multiple organ dysfunction, but do suggest that its performance can be beneficial as a bridge to AoVR. ${ }^{2}$ In this study, only two patients underwent BAV as a bridge to AoVR, and in these cases, mortality was 50\%. Recently, some studies have addressed the use of BAV as a bridge to TAVI, showing excellent results in the short and long term, when compared to BAV alone. ${ }^{6-8}$

The classification of patients according to the number of organ dysfunctions presented was of great importance to the understanding that there is a subgroup of more severe patients who evolve unfavourably, even after BAV. Patients with two or more organ dysfunctions had significantly higher mortality when compared to patients in the control group. The main reason for the treatment of patients in the group in extremis with BAV was the presence of a clinical condition of extreme gravity, whether or not with cardiac etiology, in the presence of severe aortic stenosis. It was hoped that, in these patients, the reduction of the gradient in the left ventricular (LV) outflow would provide an improvement of their LV function to the point that they could recover from the critical hemodynamic state present during their admission. However, even with the decrease of the aortic transvalvular gradient and the increase in LV ejection fraction after the procedure, these results were not translated into clinical improvement, suggesting that these patients underwent the intervention too late.

\section{Limitations of the study}

The study had some limitations, such as the small number of patients included in the retrospective analysis of data and the fact that it was conducted in a single center. 


\section{CONCLUSIONS}

Balloon aortic valvuloplasty for treatment of severe aortic stenosis with degenerative etiology has unfavorable outcome when indicated for patients with two or more organ dysfunctions, i.e., in a clinical condition in extremis.

\section{CONFLICTS OF INTEREST}

The authors declare no conflicts of interest.

\section{REFERENCES}

1. Nkomo VT, Gardin JM, Skelton TN, Gottdiener JS, Scott CG, Enriquez-Sarano M. Burden of valvular heart diseases: a population-based study. Lancet. 2006;368(9540):1005-11.

2. Bonow RO, Carabello BA, Chatterjee $K$, de Leon AC, Faxon DP, Freed MD, et al. 2008 Focused update incorporated into the ACC/AHA 2006 guidelines for the management of patients with valvular heart disease: A report of the American College of Cardiology/American Heart Association Task Force on Practice Guidelines (Writing Committee to Revise the 1998 Guidelines for the Management of Patients With Valvular Heart Disease): endorsed by the Society of Cardiovascular Anesthesiologists, Society for Cardiovascular Angiography and Interventions, and Society of Thoracic Surgeons. Circulation. 2008;118(15):e523-661.

3. Lund O. Preoperative risk evaluation and stratification of longterm survival after valve replacement for aortic stenosis: reasons for earlier operative intervention. Circulation. 1990;82(1):124-39.

4. Iung B, Baron G, Butchart EG, Gohlke-Bärwolf C, Levang OW, Tornos $\mathrm{P}$, et al. A prospective survey of patients with valvular heart disease in Europe: the Euro Heart Survey on Valvular Heart Disease. Eur Heart J. 2003;24(13):1231-43.

5. Leon MB, Smith CR, Mack M, Miller DC, Moses JW, Svensson LG, et al. Transcatheter aortic-valve implantation for aortic stenosis in patients who cannot undergo surgery. N Engl J Med. 2010;363(17):1597-607.

6. Ben-Dor I, Maluenda G, Dvir D, Barbash IM, Okubagzi P, Torguson $\mathrm{R}$, et al. Balloon aortic valvuloplasty for severe aortic stenosis as a bridge to transcatheter/surgical aortic valve replacement. Catheter CardiovascInterv. 2012 Sep 27. [Epub ahead of print]

7. Ben-Dor I, Pichard AD, Satler LF, Goldstein SA, Syed AI, Gaglia MA, et al. Complications and outcome of balloon aortic valvuloplasty in high-risk or inoperable patients. JACC Cardiovasc Interv. 2010;3(11):1150-6.

8. Ussia GP, Capodanno D, Barbanti M, Scarabelli M, Imme S, Cammalleri $\mathrm{V}$, et al. Balloon aortic valvuloplasty for severe aortic stenosis as a bridge to high-risk transcatheter aortic valve implantation. J Invasive Cardiol. 2010;22(4):161-6.

9. Otto CM, Mickel MC, Kennedy JW, Alderman EL, Bashore TM, Block PC, et al. Three-year outcome after balloon aortic valvuloplasty: insights into prognosis of valvular aortic stenosis. Circulation. 1994;89(2):642-50.

10. Lieberman EB, Bashore TM, Hermiller JB, Wilson JS, Pieper KS, Keeler GP, et al. Balloon aortic valvuloplasty in adults: Failure of procedure to improve long-term survival. J Am Coll Cardiol. 1995;26(6):1522-8.

11. Don C, Gupta PP, Witzke C, Kesarwani M, Cubeddu RJ, Inglessis I, et al. Patients with small left ventricular size undergoing balloon aortic valvuloplasty have worse intraprocedural outcomes. Catheter Cardiovasc Interv. 2012;80(6):946-54.

12. Dvir D, Sagie A, Porat E, Assali A, Shapira Y, Vaknin-Assa H, et al. Clinical profile and outcome of patients with severe aortic stenosis at high surgical risk: single-center prospective evaluation according to treatment assignment. Catheter Cardiovasc Interv. 2013;81(5):871-81.

13. Kapadia SR, Goel SS, Yuksel U, Agarwal S, Pettersson G, Svensson LG, et al. Lessons learned from balloon aortic valvuloplasty experience from the pre-transcatheter aortic valve implantation era. J Interv Cardiol. 2010;23(5):499-508.

14. Tissot CM, Attias D, Himbert D, Ducrocq G, lung B, Dilly MP, et al. Reappraisal of percutaneous aortic balloon valvuloplasty as a preliminary treatment strategy in the transcatheter aortic valve implantation era. Eurolntervention. 2011;7(1):49-56.

15. Sherman W, Hershman R, Lazzam C, Cohen M, Ambrose J, Gorlin $\mathrm{R}$. Balloon valvuloplasty in adult aortic stenosis: determinants of clinical outcome. Ann Intern Med. 1989;110(6):421-5.

16. Ben-Dor I, Goldstein SA, Pichard AD, Satler LF, Maluenda $\mathrm{G}$, Li Y, et al. Clinical profile, prognostic implication, and response to treatment of pulmonary hypertension in patients with severe aortic stenosis. Am J Cardiol. 2011;107(7): 1046-51.

17. Ben-Dor I, Pichard AD, Gonzalez MA, Weissman G, Li Y, Goldstein SA, et al. Correlates and causes of death in patients with severe symptomatic aortic stenosis who are not eligible to participate in a clinical trial of transcatheter aortic valve implantation. Circulation. 2010;122(11 Suppl):S37-42.

18. Saia F, Marrozzini C, Ciuca C, Guastaroba P, Taglieri N, Palmerini $\mathrm{T}$, et al. Emerging indications, in-hospital and long-term outcome of balloon aortic valvuloplasty in the transcatheter aortic valve implantation era. Eurolntervention.2013;8(12): 1388-97.

19. Solomon LW, Fusman B, Jolly N, Kim A, Feldman T. Percutaneous suture closure for management of large French size arterial puncture in aortic valvuloplasty. J Invasive Cardiol. 2001;13(8):592-6. 